\begin{tabular}{|c|l|}
\hline Title & Influence of zincate pretreatment on adhesion strength of a copper electroplating layer on AZ91 D magnesium al loy \\
\hline Author(s) & Tang, Jinwei; A zumi, Kazuhisa \\
\hline Citation & $\begin{array}{l}\text { Surface and Coatings Technology, 205(8-9), 3050-3057 } \\
\text { https://doi.org/10.1016/.surfcoat.2010.11.021 }\end{array}$ \\
\hline Issue Date & 2011-01-25 \\
\hline Doc URL & http://hdl.handle.net/2115/45133 \\
\hline Type & article(author version) \\
\hline File Information & SCT 205-89_3050-3057.pdf \\
\hline
\end{tabular}

Instructions for use 


\title{
Influence of zincate pretreatment on adhesion strength of a copper electroplating layer on AZ91 D magnesium alloy
}

\author{
Jinwei Tang*, Kazuhisa Azumi \\ Graduate School of Engineering, Hokkaido University, N13W8, Kitaku, Sapporo 060-8628, \\ Japan \\ *Corresponding Author: Tel: +81 11706 6749; Fax: +81 117067897. \\ E-mail address: tangjw1984@gmail.com.
}

\begin{abstract}
Cu was electrodeposited on AZ91 D Mg alloy with zincate pretreatment in an alkaline plating bath, and the effect of zincate pretreatment on adhesion strength of the Cu layer was investigated. Scanning electron microscopy results showed that Zn was mainly deposited on the $\alpha$-phase surface, and ultrasonic agitation at the initial stage of the zincate pretreatment improved the coverage of the Zn layer even on the $\beta$-phase surface, resulting in enhancement of the adhesion strength of the $\mathrm{Zn}$ layer and the successive $\mathrm{Cu}$ layer to the substrate.

Adhesion tests revealed that the plating layer peeled off at the mixed layer of $\mathrm{Zn}$ and $\mathrm{Cu}$ deposits formed at the interface between the zincated layer and the electrodeposited Cu layer. A smooth $\mathrm{Cu}$ surface was obtained in the plating bath containing $\mathrm{H}_{3} \mathrm{BO}_{3}$.
\end{abstract}

Key words: AZ91 D Mg alloy, Zincate pretreatment, Copper electrodeposition, Adhesion strength 


\section{Introduction}

Owing to their superior strength, light weight and rich natural resources, $\mathrm{Mg}$ and its alloys are attractive materials in various applications including applications in aerospace, automobile and mobile electronics industries. Unfortunately, corrosion resistivity of $\mathrm{Mg}$ alloys is weak and the usage of Mg alloys has therefore been limited to indoor conditions. The surface of Mg is easily covered with an oxide or hydroxide layer with a high electric resistance, which may not be suitable for some applications in electronic devices. Therefore, it is important to establish a plating method that can produce functional coatings on $\mathrm{Mg}$ alloys such as corrosion-resistant and electrically conductive coatings with sufficient adhesion strength.

Several methods for producing corrosion-resistant coatings on Mg alloys, including metal coatings [1], conversion coatings [2, 3], anodizing [4], organic coatings [5] and vaporphase processes [6] have been proposed, compared with these methods, electrodeposition is a relatively economical and convenient technique. Since a thick passivation film is formed on $\mathrm{Mg}$ in the ambient atmosphere, pretreatment is necessary to remove the surface layer and to suppress its reformation prior to the plating process [7-10]. It is also important to obtain a uniform surface condition on Mg alloys for plating because intermetallic compounds such as $\mathrm{Mg}_{\mathrm{x}} \mathrm{Al}_{\mathrm{y}}$ are formed at grain boundaries. Despite these difficulties, electroplating can potentially provide uniform coatings with good corrosion resistance for $\mathrm{Mg}$ alloys. Huang et al. [11] proposed a environment-friendly pretreatment with galvanostatic etching to obtain an adherent and uniformly covered copper deposit on pure Mg and Mg alloys of AZ31 and AZ61 in the alkaline Cu sulfate plating bath. Dennis et al. [12, 13] studied the effects of three proprietary pretreatment sequences, i.e., the Dow process, the Norsk-Hydro process and the WCM canning process on various Mg alloy diecasts, e.g. AZ91CC (Cold Chamber), AZ61CC, AZ91HC (Hot Chamber) and AZ71HC. Satisfactory peeling-adhesion at $7.7 \mathrm{kN} \mathrm{m}^{-}$

${ }^{1}$ was obtained for AZ61CC using a WCM process, and found that the comparatively low adhesion obtained for AZ91HC was due to its poor surface quality induced in the casting process. They also investigated the role of fluoride contained in the bath at the activation and zincating stages of the WCM process, and found that fluoride suppressed the Zn deposition in the zincate pretreatment and thus elongate the zincate process. Generally, metal electroplating is performed by the following processes: surface cleaning, acid pickling, activation, zincating, and metal electrodeposition. However, highly toxic chromic acid has sometimes been used in the acid pickling process, and poisonous cyanide has also sometimes been used in $\mathrm{Cu}$ 
electrodeposition to improve the adhesion strength of $\mathrm{Cu}$ layer to the Mg alloy substrate [1214]. Moreover, zincate pretreatment has been carried out at $70-80^{\circ} \mathrm{C}$, temperatures at which the composition of the zincate bath may change due to rapid water evaporation, resulting in low reproducibility of pretreatment for an $\mathrm{Mg}$ alloy.

In this study, zincate pretreatment was carried out for AZ91 D Mg alloy at room temperature to investigate its mechanism and to establish a reproducible pretreatment condition. Cu was then electrodeposited on AZ91 D Mg alloy in an alkaline plating bath. The effects of different pretreatment on adhesion strength of the Cu electroplating layer to AZ91 D Mg alloy were investigated. The effect of ultrasonic agitation in the zincating process on adhesion strength was also examined. All of the conditions used in this work were mild and all of the processes were simple, and the plating baths did not contain any highly toxic chemical species.

\section{Experimental}

Specimens were prepared from an AZ91 D (die-cast) Mg alloy sheet, and composed of $9.22 \mathrm{wt} \% \mathrm{Al}, 0.72 \mathrm{wt} \% \mathrm{Zn}, 0.418 \mathrm{wt} \% \mathrm{Mn}$, and bal. Mg. The testing specimens were cut into rectangular pieces in the size of $10 \mathrm{~mm} \times 10 \mathrm{~mm} \times 9 \mathrm{~mm}$ or $30 \mathrm{~mm} \times 30 \mathrm{~mm} \times 9 \mathrm{~mm}$. The specimens were embedded in resin, and the exposed surfaces of $100 \mathrm{~mm}^{2}$ or $900 \mathrm{~mm}^{2}$ were mechanically polished with SiC papers of 700, 1000, and 1500 grits. They were then cleaned with distilled water and dried with a stream of air. Compositions and operation conditions of the pickling (activation) pretreatment, zincate pretreatment and $\mathrm{Cu}$ electroplating are shown in Table 1. Milli-Q filtered water and analytical-grade chemicals were used for preparation of all solutions. The samples were washed with distilled water after each treatment and immersed immediately in the next bath to avoid drying. In some zincate pretreatment specimen was irradiated by the ultrasonic sound in water bath at room temperature by using an USK-4R ultrasonic cleaner (AS ONE Co., Japan, $40 \mathrm{kHz}$ in frequency, $160 \mathrm{~W}$ in output power). The temperature of the bath slightly rose after long term irradiation. A potentio/galvanostat (Ivium Technologies, model IviumStat) was employed for $\mathrm{Cu}$ electrodeposition by using a typical three-electrode system consisting of a working electrode (WE) of AZ91 D Mg alloy, an Ag/AgCl reference electrode (RE) and a counter electrode (CE) of a copper plate (99.99\%). In this paper, electrode potential is presented as a value vs. $\mathrm{Ag} / \mathrm{AgCl}-\mathrm{RE}$. Cu was electrodeposited in an alkaline plating bath (Fehling's solution) with current density of $-8 \mathrm{~mA} \mathrm{~cm}^{-2}$ under a stirring condition. In order to investigate the effect of 
$\mathrm{H}_{3} \mathrm{BO}_{3}$, the $\mathrm{Cu}$ plating bath was prepared with or without the addition of $\mathrm{H}_{3} \mathrm{BO}_{3}$ as shown in Table 1. All electrochemical experiments were conducted at room temperature. Adhesion strength of the $\mathrm{Zn}$ layer and the Cu electroplating layer to the substrate was measured by using a pull-off adhesion tester (Elcometer 106). A scanning electron microscope (SEM) combined with energy dispersive X-ray spectroscopy (EDX, EDXS) (JEOL Co., model no. JSM-6500F) was used to observe the surface morphology and elemental composition of the coatings.

\section{Results and discussion}

\subsection{Analysis of the zincating process}

Formation of a Zn coating on AZ91 D Mg alloy was studied by measuring the variation of open circuit potential, $E_{\mathrm{OC}}$, with immersion time in the zincate bath as shown in Fig. 1. The curve can be divided into three stages. The first stage showed decrease in $E_{\mathrm{OC}}$ from approximately $-1.35 \mathrm{~V}$ at the initial time of immersion to ca. $-1.74 \mathrm{~V}$ at $130 \mathrm{~s}$, suggesting active dissolution of the substrate in this period. In the second stage, $E_{\mathrm{OC}}$ increased rapidly in the noble direction, reaching about $-1.32 \mathrm{~V}$ at $250 \mathrm{~s}$. This potential shift indicates that $\mathrm{Zn}$ was deposited rapidly on the substrate. In the third stage, $E_{\mathrm{OC}}$ shifted slowly to reach a steady potential at ca. $-1.3 \mathrm{~V}$, which was less-noble than the OCP at $-1.25 \mathrm{~V}$ measured for Zn plate. The $0.05 \mathrm{~V}$ difference between the two situations indicated that the $\mathrm{Zn}$ layer deposited on AZ91 D Mg alloy did not covered completely the AZ91 D surface to enable slight dissolution of Mg surface.

AZ91-type alloy is a Mg-Al binary phase system composed of two main phases: a Mg-rich $\alpha$-phase and an $\mathrm{Al}$-rich $\beta$-phase, $\mathrm{Mg}_{17} \mathrm{Al}_{12}$ [16]. Corrosion of this type of $\mathrm{Mg}$ alloy in an aqueous environment was accelerated by galvanic coupling between the anode of the $\alpha$ phase surface and the cathode of the $\beta$-phase surface, resulting in non-uniform dissolution between the two phases. The cathodic reaction of hydrogen evolution occurs mainly on the $\beta$ phase surface rather than on the $\alpha$-phase surface because the overvoltage of this reaction on the former is smaller than that on latter $[17,18]$. In order to investigate the process of $\mathrm{Zn}$ deposition, SEM images were taken for samples at different zincating times as shown in Fig.

2. After the picking process, the substrate surface was smooth, and the slightly dissolved $\alpha$ phase surface and $\beta$-phase surface were distinguishable as shown in Fig. 2(a). The sample after 60-s immersion shows formation of a corrosion film on the surface as can be seen in Fig. 2(b), corresponding to stage 1 of the rapid dissolution process shown in Fig. 1. After $200 \mathrm{~s}$, 
the corrosion film on the $\alpha$-phase surface began to peel off and then $\mathrm{Zn}$ was deposited on a fresh surface as shown in Fig. 2(c). After 500 s, $\alpha$-phase surface was almost fully covered with a $\mathrm{Zn}$ layer, while the $\beta$-phase surface was still covered with the corrosion film as shown in Fig. 2(d). After 1000 s, a dense and compact Zn layer covered the $\alpha$-phase surface, but the $\beta$-phase surface was still covered with the corrosion film as shown in Fig. 2(e). This result was confirmed by EDXS observation as shown in Fig.2. The mechanism for such nonuniform deposition of $\mathrm{Zn}$ will be discussed later. In order to evaluate the thickness of the $\mathrm{Zn}$ layer deposited on the $\alpha$-phase surface after zincate preparation for $1000 \mathrm{~s}$, a cross-sectional SEM image was taken as shown in Fig. 2(f). The dense Zn layer with approximately $1 \mu \mathrm{m}$ had adhered properly to the substrate and exhibited an excellent adhesion strength property as shown later.

When Mg is immersed in zincate solution, the following reactions occur [9]:

$$
\begin{aligned}
& 2 \mathrm{Mg}(\mathrm{OH})_{2}+\mathrm{xP}_{2} \mathrm{O}_{7}^{4-} \rightarrow\left[\mathrm{Mg}_{2}\left(\mathrm{P}_{2} \mathrm{O}_{7}\right)_{\mathrm{x}}\right]^{4-4 \mathrm{x}}+4 \mathrm{OH}^{-} \\
& \mathrm{Mg} \rightarrow \mathrm{Mg}^{2+}+2 \mathrm{e}^{-} \\
& \mathrm{Zn}^{2+}+2 \mathrm{e}^{-} \rightarrow \mathrm{Zn} \\
& 2 \mathrm{H}_{2} \mathrm{O}+2 \mathrm{e}^{-} \rightarrow 2 \mathrm{OH}^{-}+\mathrm{H}_{2} \uparrow \\
& \mathrm{Mg}^{2+}+2 \mathrm{OH}^{-} \rightarrow \mathrm{Mg}(\mathrm{OH})_{2} \\
& \mathrm{Mg}^{2+}+2 \mathrm{~F}^{-} \rightarrow \mathrm{MgF}_{2}
\end{aligned}
$$

Fig. 3 shows a schematic presentation of the zincate pretreatment process for AZ91 D Mg alloy. Initially, the thin $\mathrm{Mg}(\mathrm{OH})_{2}$ film reacted with pyrophosphate to form a soluble complex and thus the Mg substrate was exposed. Both $\alpha$-phase and $\beta$-phase were dissolved and some kind of corrosion film was formed on the substrate. Dissolution of $\mathrm{Mg}$ on the $\beta$-phase surface caused enrichment of the surface concentration of $\mathrm{Al}$ and thus an $\mathrm{Al}$ hydroxide film was formed, obstructing electron transfer necessary for Zn deposition. On the other hand, the corrosion film formed on the $\alpha$-phase surface was mainly composed of Mg hydroxide with rather low density, which was gradually dissolved by pyrophosphate. This allowed Zn ions to reach the substrate through the corrosion film and to be reduced to form $\mathrm{Zn}$ deposits at the interface between the corrosion film and $\alpha$-phase surface. The area of Zn deposits increased rapidly as the corrosion film was detached from the $\alpha$-phase surface. Mg dissolution reaction was slowed down when the surface was covered with Zn deposits, and finally the $\alpha$-phase surface of the Mg alloy was almost entirely covered with a Zn layer.

As discussed in Fig. 2 and Fig. 3, initial stage of zincate pretreatment of AZ91 D Mg alloy contains peeling off of the corrosion layer and following Zn deposition on $\alpha$-phase 
surface. On the $\beta$-phase surface, however, Al rich corrosion film was not peeled off and disturbed Zn deposition. It was expected that ultrasonic irradiation would promote the mechanical peeling off of the corrosion layer and thus Zn deposition both on the $\beta$-phase surface. Sheng et al. [19] reported that ultrasonic irradiation at the early stage of the treatment affected the density and size of phosphate deposits probably due to agitation effect of local mass transportation. Therefore, in order to improve the quality of the $\mathrm{Zn}$ layer, ultrasonic irradiation was applied to the initial stage of the zincate pretreatment for 240 s. Fig. 4 shows SEM images of Zn-coated samples prepared with (b and $\mathbf{d}$ ) or without (a and $\mathbf{c}$ ) ultrasonic agitation. The non-agitated sample shows Zn deposition on the $\alpha$-phase surface but not on the $\beta$-phase surface. Cracks were observed on the $\beta$-phase surface, and these cracks were probably formed in the Al hydroxide layer due to the drying process at the SEM observation. Observation of the samples prepared with ultrasonic agitation showed that most of the $\beta$ phase surface was covered with a porous Zn layer. Such a porous structure was expected to improve adhesion strength of the successive electroplated $\mathrm{Cu}$ layer to the substrate.

\subsection{Electrodeposition of copper}

$\mathrm{H}_{3} \mathrm{BO}_{3}$ has often been added to plating baths to maintain proper $\mathrm{pH}$ at the substratesolution interface. Hoare et al. observed a remarkable effect of $\mathrm{H}_{3} \mathrm{BO}_{3}$ in ultrahigh-speed plating of nickel [20]. They suggested that $\mathrm{H}_{3} \mathrm{BO}_{3}$ in the Watts bath acted not only as a $\mathrm{pH}$ buffer but also as a homogeneous catalyst by forming a complex with $\mathrm{Ni}$ ions to lower the overvoltage for nickel deposition [21]. Karwas et al. also found that the addition of $\mathrm{H}_{3} \mathrm{BO}_{3}$ to a Co-Zn plating bath increased nucleation density of the deposits, content of $\mathrm{Zn}$ in the deposited alloy, and current efficiency of the electrodeposition [22]. They attributed these effects to the interaction of adsorbed $\mathrm{H}_{3} \mathrm{BO}_{3}$ on the electrode.

In order to investigate the effect of addition of $\mathrm{H}_{3} \mathrm{BO}_{3}$ to $\mathrm{Cu}$ electroplating layer on Mg alloy, plating baths were prepared with and without the addition of $\mathrm{H}_{3} \mathrm{BO}_{3}$ as shown in Table 1. After the zincate pretreatment combined with ultrasonic agitation, the sample was electroplated with $\mathrm{Cu}$. Fig. 5 shows the time-transition of the electrodeposition potential, $E_{\mathrm{ED}}$, of Zn-coated AZ91 D Mg alloy during galvanostatic Cu electrodeposition in the bath with or without addition of $\mathrm{H}_{3} \mathrm{BO}_{3}$. At the initial stage, $E_{\mathrm{ED}}$ increased rapidly from less-noble potential and reached around $-0.95 \mathrm{~V}$ within ca. $150 \mathrm{~s}$ and then increased slowly in the following electrodeposition process. During the electrodeposition process, $E_{\mathrm{ED}}$ measured in the $\mathrm{H}_{3} \mathrm{BO}_{3}$-containing bath was more noble than that in the bath without $\mathrm{H}_{3} \mathrm{BO}_{3}$. This 
phenomenon was similar to the result reported for Ni deposition mentioned above [21], i.e., boric ions may form a complex with $\mathrm{Cu}$ ions or adsorb on the depositing surface to reduce the overpotential for electrodeposition reaction of $\mathrm{Cu}$.

Fig. 6 shows SEM images of AZ91 D Mg alloy surfaces after Cu electrodeposition in baths with and without $\mathrm{H}_{3} \mathrm{BO}_{3}$. Although dense and compact $\mathrm{Cu}$ layer were obtained in both cases, a smooth surface was obtained in the bath containing $\mathrm{H}_{3} \mathrm{BO}_{3}$. This is related to the smaller overpotential for $\mathrm{Cu}$ electrodeposition in the bath containing $\mathrm{H}_{3} \mathrm{BO}_{3}$, which absorbed the active sites for hydrogen evolution reaction and thus suppressed the gas evolution during the plating [23].

\subsection{Adhesion tests}

Results of adhesion strength tests of the plating layer to the substrate are summarized in Table 2. Better adhesion was always obtained for the samples prepared with ultrasonic agitation in the zincate pretreatment process. Improvement in adhesion strength due to ultrasonic agitation seems to be provided by increase in the $\mathrm{Zn}$-coated area on the $\beta$-phase surface and its porous structure as shown in Fig. 4. Fig. 7 shows photos of zincated sample prepared with ultrasonic agitation after the pull-off adhesion test. The substrate surface shown in Fig. 7(a) indicates that the Zn layer remained on the $\alpha$-phase surface, and the Zn deposits on the $\beta$-phase surface peeled off from the substrate as shown in Fig. 7(b). This means that adhesion of the Zn layer was mainly maintained by the Zn deposits on the $\alpha$-phase surface. The low adhesivity of $\mathrm{Zn}$ deposits on the $\beta$-phase surface is probably due to the existence of a residual corrosion layer on the $\beta$-phase surface.

Fig. 8 shows photos and SEM images of Cu layer on AZ91 D Mg alloy prepared with zincate pretreatment and ultrasonic agitation after the pull-off test. EDS analysis was also applied to the substrate surface (Fig. 8(a)) and dolly surface (Fig. 8(b)) to distinguish the elements remaining on these surfaces. $\mathrm{Zn}$ and $\mathrm{Cu}$ were detected on the $\alpha$-phase surface of the substrate (location 1 in Fig. 8(a)) and at the location on the dolly surface corresponding to the $\alpha$-phase surface before peeling off (location 1 in Fig. 8(b)). On the other hand, signal of Zn or $\mathrm{Cu}$ was low on the $\beta$-phase surface of the substrate (location 3 in Fig. 8(a)), and $\mathrm{Zn}$ or Cu was mainly detected on the dolly surface at the location corresponding to the $\beta$-phase surface (locations 3 and 2 in Fig. 8(b)). A part of the Zn film on the $\alpha$-phase surface near the $\beta$-phase was also peeled off (location 2 in Fig. 8(a)). Based on these results, it can be concluded that the plating layer on the $\beta$-phase surface peeled off easily and transferred to the dolly side. On 
the other hand, adhesion of the plating layer on the $\alpha$-phase surface is relatively strong. Since the deposits remaining on the $\alpha$-phase surface and the deposits transferred to the dolly showed signals of $\mathrm{Zn}$ and $\mathrm{Cu}$, peeling off seems to occur by cleavage of a mixed layer of $\mathrm{Zn}$ and $\mathrm{Cu}$ deposits. The formation of this mixed layer will be discussed below.

Cross-sectional SEM image of the plating layer peeled off from the AZ91 D Mg alloy substrate is shown in Fig. 9. The combination of SEM observation and EDS analyses indicated that the mixed layer of $\mathrm{Zn}$ and $\mathrm{Cu}$ had adhered properly to the $\mathrm{Cu}$ layer. This result confirmed that adhesion strength of the Cu layer to the AZ91 D Mg alloy substrate was mainly determined by this mixed layer. The peeling-off process of the $\mathrm{Cu}$ layer from the AZ91 D Mg alloy substrate zincate-pretreated with ultrasonic agitation is schematically presented in Fig. 10. A mixed layer of $\mathrm{Zn}$ and $\mathrm{Cu}$ was formed between the $\mathrm{Zn}$ layer and $\mathrm{Cu}$ layer because $\mathrm{Cu}$ was deposited rapidly on the substrate not only through the $\mathrm{Cu}$ electrodeposition process but also through the substitution reaction of $\mathrm{Zn}$ dissolution and $\mathrm{Cu}$ deposition. This process may have started immediately after the specimen had been immersed in the $\mathrm{Cu}$ plating bath and then $\mathrm{Zn}$ was electrodeposited within the $\mathrm{Cu}$ layer again. Results of the pull-off adhesion test indicated the quality of this mixed layer determines the overall adhesion strength. Further optimization of the zincate pretreatment process is thus necessary.

\section{Conclusions}

In this study, a Cu layer was electrodeposited on AZ91 D Mg alloy prepared with zincate pretreatment and the following conclusions could be drawn from the experimental results:

1. In the zincate pretreatment process, $\mathrm{Zn}$ is mainly deposited on the $\alpha$-phase surface rather than on the $\beta$-phase surface because the latter is covered with a corrosion layer.

2. Adhesion strength of the Zn layer is mainly determined by the Zn deposits on the $\alpha$-phase surface. Ultrasonic agitation at the initial stage of the zincating process improves the coverage of $\mathrm{Zn}$ deposits on the $\beta$-phase surface and thus improves adhesion strength.

3. A dense and compact $\mathrm{Cu}$ layer can be electrodeposited on zincate pretreated AZ91 D Mg alloy prepared with ultrasonic agitation. Addition of $\mathrm{H}_{3} \mathrm{BO}_{3}$ to the plating bath improves the smoothness of $\mathrm{Cu}$ layer.

4. A mixed layer of $\mathrm{Zn}$ and $\mathrm{Cu}$ is formed between the $\mathrm{Zn}$ layer and $\mathrm{Cu}$ layer. Adhesion strength of the $\mathrm{Cu}$ layer is mainly determined by this mixed layer. 


\section{Acknowledgments}

This work was supported by the Global COE Program (Project No. B01: Catalysis as the Basis for Innovation in Materials Science) from the Ministry of Education, Culture, Sports, Science and Technology, Japan and also supported in part by the Light Metal Educational Foundation.

\section{References}

[1] J.K. Chang, S.Y. Chen, W.T. Tsai, M.J. Deng, IW. Sun, Electrochem. Conmmun., 9 (2007) 1602.

[2] H.H. Elsentriecy, K. Azumi, J. Electrochem. Soc., 156 (2009) D70.

[3] H.H. Elsentriecy, K. Azumi, H. Konno, Electrochim. Acta, 53 (2007) 1006.

[4] D.P. Barbosa, G. Knörnschild, Surf. Coat. Technol., 203 (2009) 1629.

[5] F. Zucchi, A. Frignani, V. Grassi, A. Balbo, G. Trabanelli, Mater. Chem. Phys., 110 (2008) 263.

[6] K.-T. Rie, J.Wöhle, Surf. Coat. Technol., 112 (1999) 226.

[7] Y.P. Zhu, G. Yu, B.N. Hu, X.P. Lei, H.B. Yi, J. Zhang, Appl. Surf. Sci., 256 (2010) 2988.

[8] X.M. Wang, L.Q. Zhu, H.C. Liu, W.P. Li, Surf. Coat. Technol., 202 (2008) 4210.

[9] Z.P. Zhang, G. Yu, Y.J. Ouyang, X.M. He, B.N. Hu, J. Zhang, Z.J. Wu, Appl. Surf. Sci., 255 (2009) 7773.

[10] L.Q. Zhu, W.P. Li, D.D. Shan, Surf. Coat. Technol., 201 (2006) 2768.

[11] C.A. Huang, T.H. Wang, T. Weirich, V. Neubert, Corros. Sci., 50 (2008) 1385.

[12] J.K. Dennis, M.K.Y.Y. Wan, S.J. Wake, Trans. Inst. Met. Finish., 63 (1985) 74.

[13] J.K. Dennis, M.K.Y.Y. Wan, S.J. Wake, Trans. Inst. Met. Finish., 63 (1985) 81.

[14] L.F. Spencer, Met. Finish., 68 (1970) 32.

[15] H.H. Elsentriecy, K. Azumi, H. Konno, Surf. Coat. Technol., 202 (2007) 532.

[16] G. Ballerini, U. Bardi, R. Bignucolo, and G. Ceraolo, Corros. Sci., 47 (2005) 2173.

[17] G. Song, A. Atrens, X. Wu, and B. Zhang, Corros. Sci., 40 (1998) 1769.

[18] G. Baril, C. Blanc, and N. Pebere, J. Electrochem. Soc., 148 (2001) B489.

[19] M. Sheng, C. Wang, Q. Zhong, Y. Wei, Y. Wang, Ultrason. Sonochem., 17 (2010) 21.

[20] J.P. Hoare, B.J. Howie and M.A. Laboda, Plat. Surf. Finish., 73 (1986) 62.

[21] J. P. Hoare, J. Electrochem. Soc., 133 (1986) 2491.

[22] C. Karwas and T. Hepel, J. Electrochem. Soc., 136 (1989) 1672.

[23] J. Horkans, J. Electrochem. Soc., 126 (1979) 1861. 
Table 1. Bath composition and operating conditions for the zincate pretreatment and for electrodeposition of $\mathrm{Cu}$ on AZ91 D Mg alloy.

\begin{tabular}{llll}
\hline Process & Bath composition & Concentration $\left(\mathrm{gL}^{-1}\right)$ & Condition \\
\hline Pickling [15] & $\mathrm{HF}+\mathrm{HCl}$ & $0.25 \mathrm{wt} \%$ each & Room temperature, 20s \\
\hline \multirow{2}{*}{ Zincate pretreatment } & $\mathrm{ZnSO}_{4} \cdot 7 \mathrm{H}_{2} \mathrm{O}$ & 46 & $\mathrm{pH} 10.40 \pm 0.02$ \\
& $\mathrm{~K}_{4} \mathrm{P}_{2} \mathrm{O}_{7}$ & 139 & Room temperature, 1000s \\
& $\mathrm{Na}_{2} \mathrm{CO}_{3}$ & 5 & \\
& $\mathrm{KF}$ & 6 & $\mathrm{pH} 13.50 \pm 0.02$ (without \\
& & 70 & $\left.\mathrm{H}_{3} \mathrm{BO}_{3}\right)$ \\
\hline Cu electrodeposition & $\mathrm{CuSO}_{4} \cdot 5 \mathrm{H}_{2} \mathrm{O}$ & 346 & Room temperature, \\
(Fehling's solution) & $\mathrm{KNaC}_{4} \mathrm{H}_{4} \mathrm{O}_{6} \cdot 4 \mathrm{H}_{2} \mathrm{O}$ & 120 & Under stirring (600rpm) \\
& $\mathrm{NaOH}$ & 0 or 20 & \\
& $\mathrm{H}_{3} \mathrm{BO}_{3}$ & &
\end{tabular}


Table 2. Adhesion strength of $\mathrm{Cu}$ or $\mathrm{Cu} / \mathrm{Zn}$ plating layer deposited on AZ91 D Mg alloy measured by using a pull-off adhesion tester. Values are averaged data of three runs for each condition.

\begin{tabular}{lcccc}
\hline Coating & $\mathrm{Zn}$ & $\mathrm{Zn}$ & $\mathrm{Zn}+\mathrm{Cu}$ & $\mathrm{Zn}+\mathrm{Cu}$ \\
\hline Ultrasonic agitation & Yes & & Yes & \\
\hline Adhesion strength $(\mathrm{MPa})$ & 10 & 9 & 9 & 7 \\
\hline
\end{tabular}




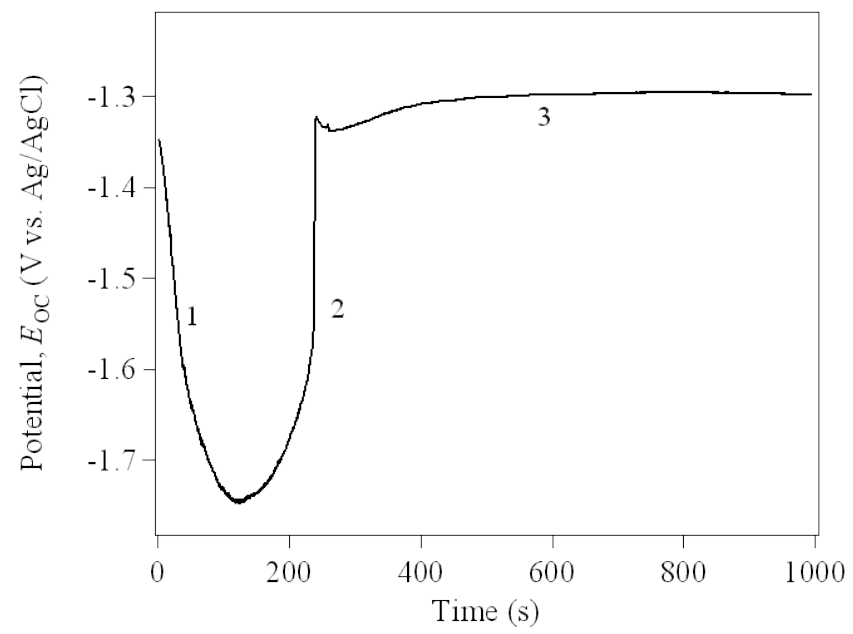

Fig. 1 Change in OCP, $E_{\mathrm{OC}}$, of AZ91 D Mg alloy during the zincate pretreatment process. 

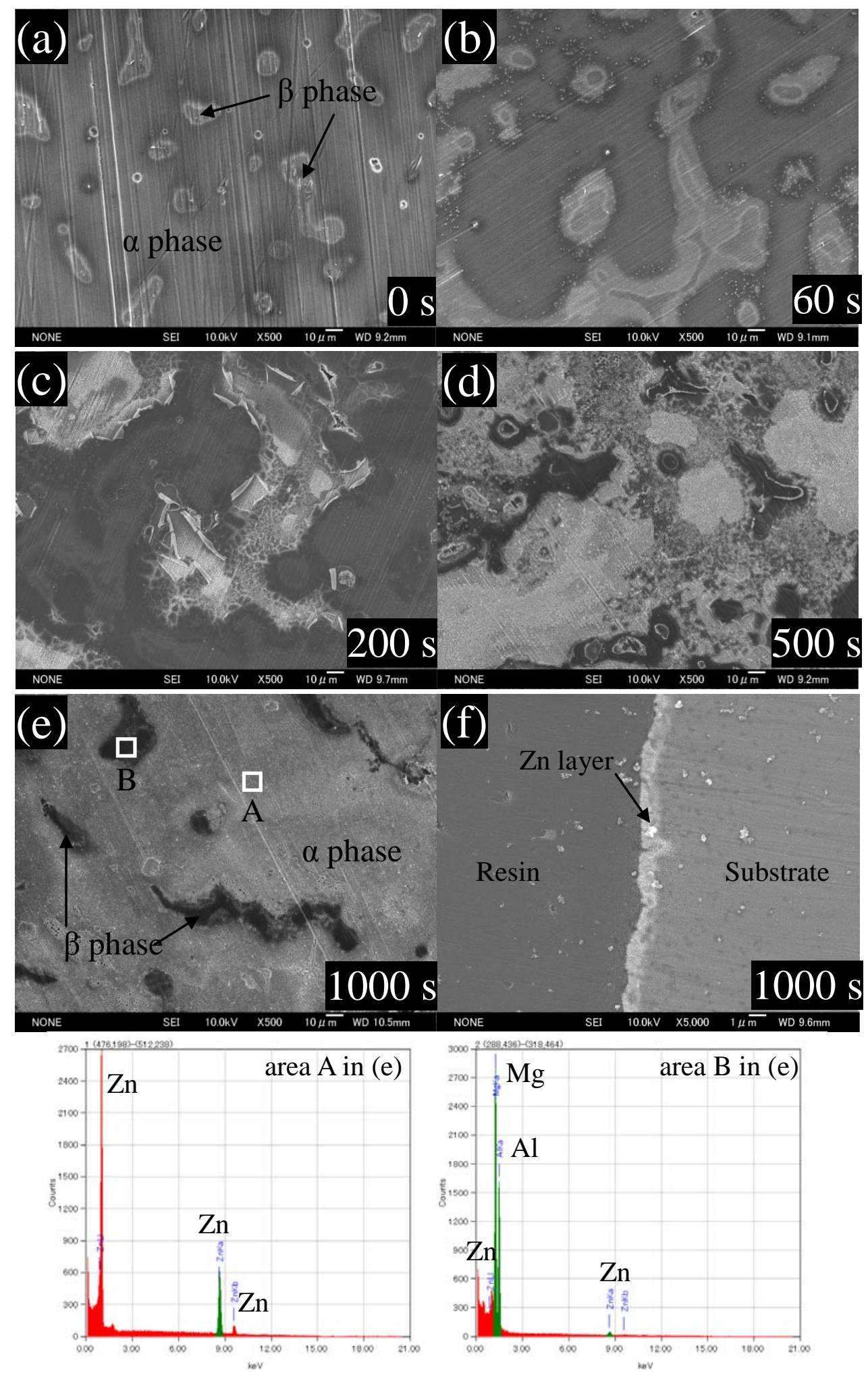

Fig. 2 Upper: SEM images of the surface (a-e) of AZ91 D Mg alloy after zincate pretreatment for different times. (f) Cross-sectional SEM image of sample (e). Lower: EDS analysis of sample (e) at different positions A and $\mathrm{B}$. 


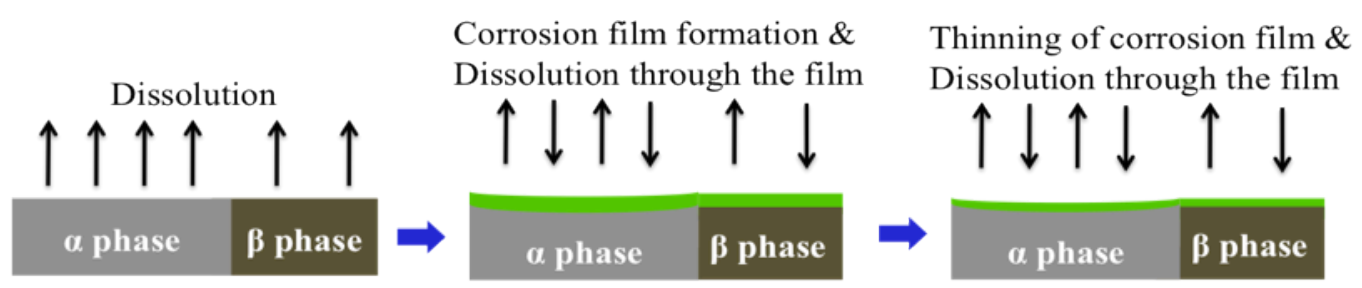

AZ91D Mg alloy

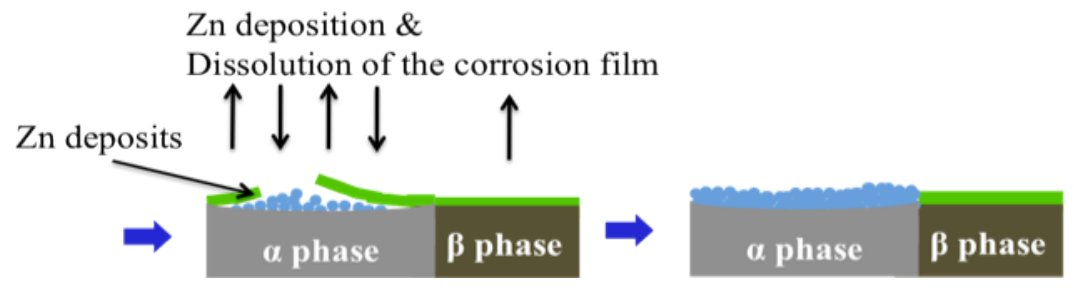

Fig. 3 Schematic representation of the zincate pretreatment process for AZ91 D Mg alloy. 

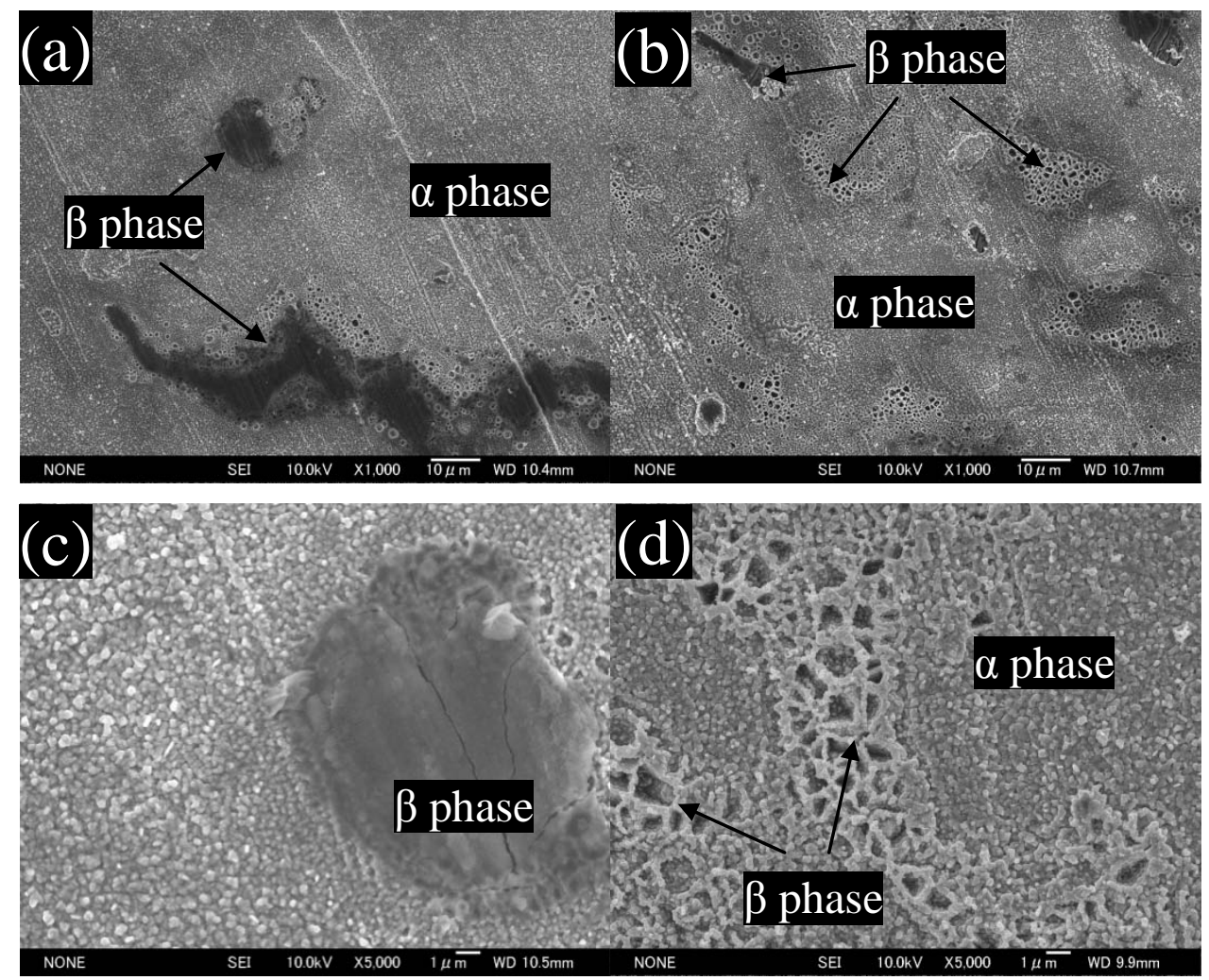

Fig. 4 SEM images of AZ91 D Mg alloy after zincate pretreatment for $1000 \mathrm{~s}$ without $(\mathrm{a}, \mathrm{c})$ or with $(\mathrm{b}, \mathrm{d})$ ultrasonic agitation for $240 \mathrm{~s}$ at the initial stage of the zincate pretreatment process. 


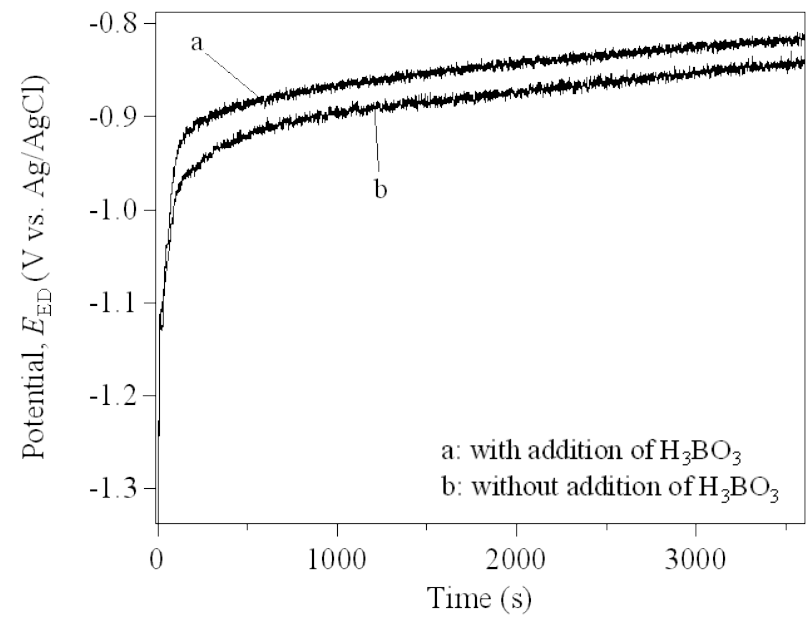

Fig. 5 Potential-time transition of AZ91 D Mg alloy during galvanostatic electrodeposition of $\mathrm{Cu}$ in baths with and without $\mathrm{H}_{3} \mathrm{BO}_{3}$. 

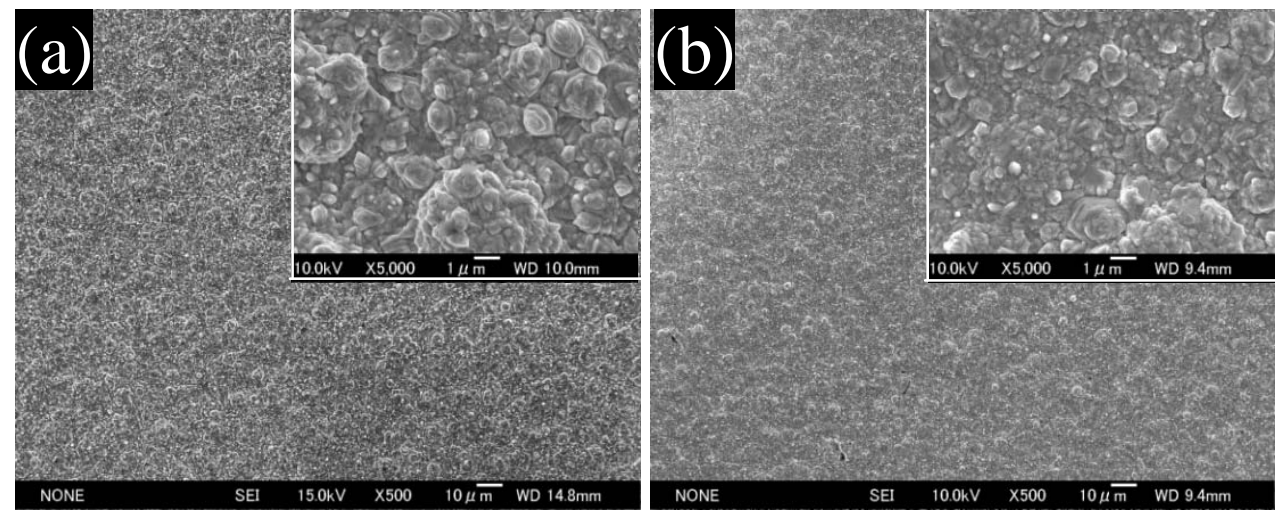

Fig. 6 SEM images of the AZ91 D Mg alloy surface after Cu electrodeposition in plating baths (a) without and (b) with $\mathrm{H}_{3} \mathrm{BO}_{3}$. 


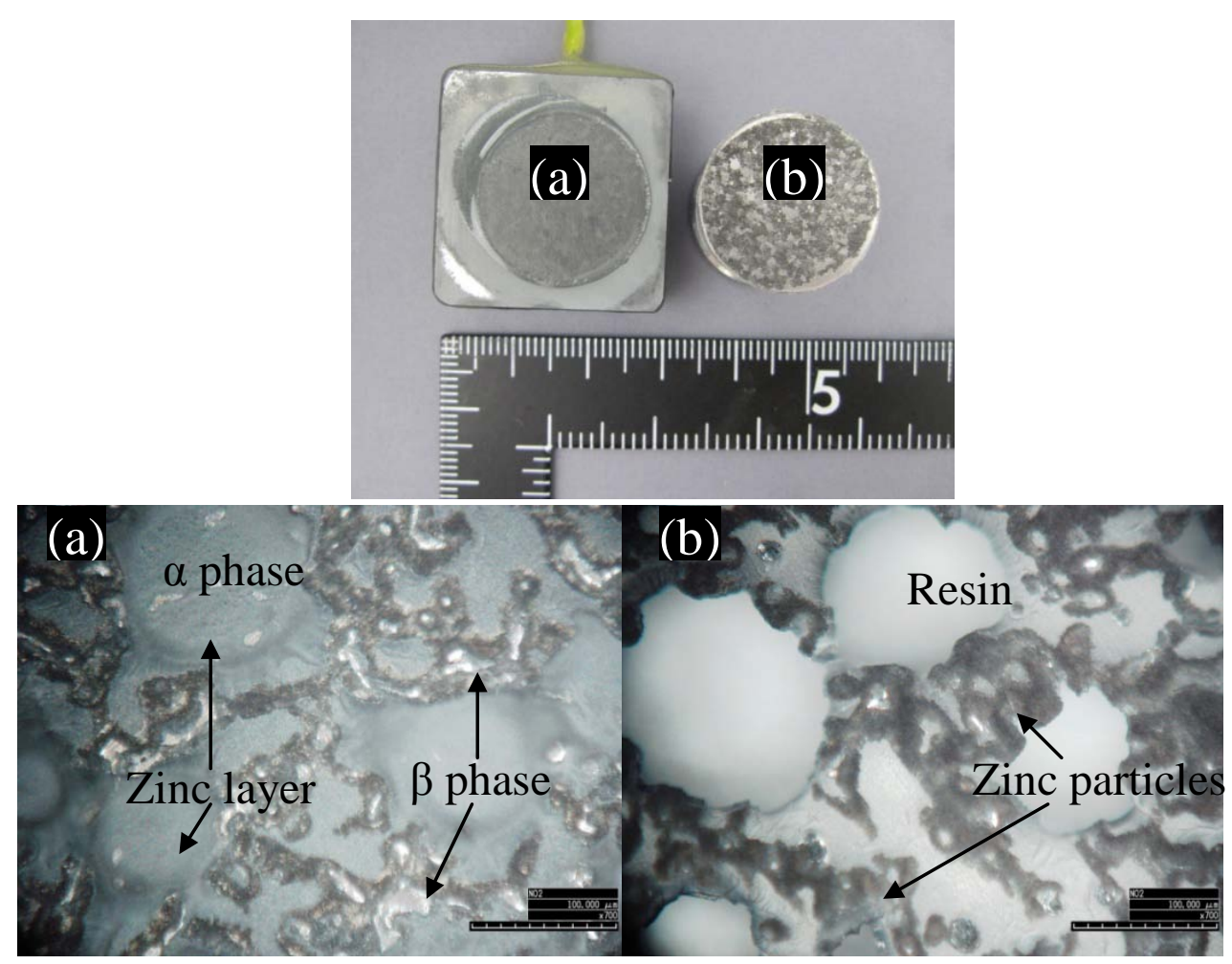

Fig. 7 (Color online) Photos of zincated sample prepared with ultrasonic agitation after the pull-off adhesion test: (a) surface of the substrate and (b) surface of the dolly. 


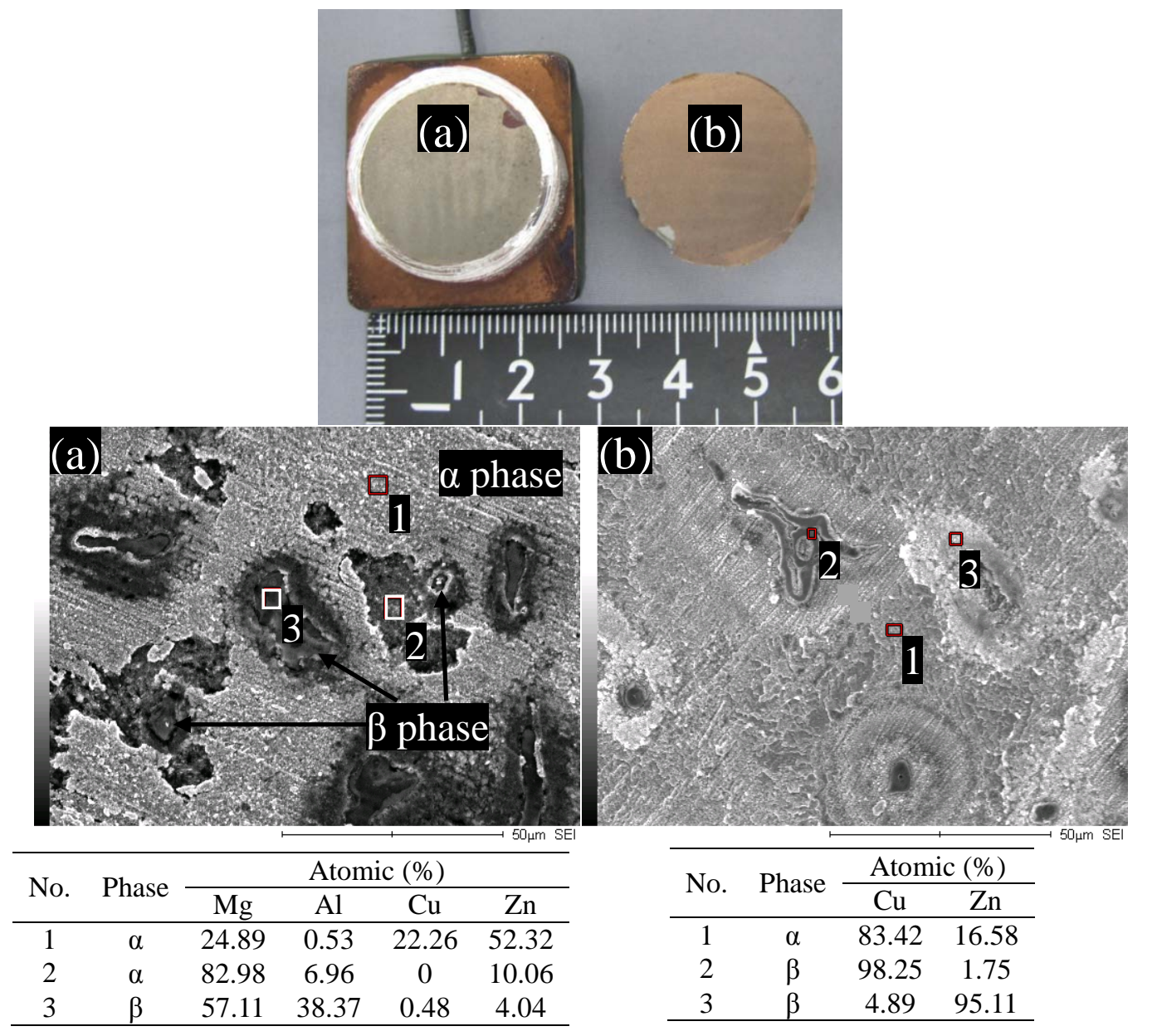

Fig. 8 (Color online) Upper: Photos of Cu-coated AZ91 D Mg alloy after the pull-off adhesion test. (a) surface of substrate, (b) surface of dolly. Lower: SEM images and EDS analysis at different positions on (a) and (b). 

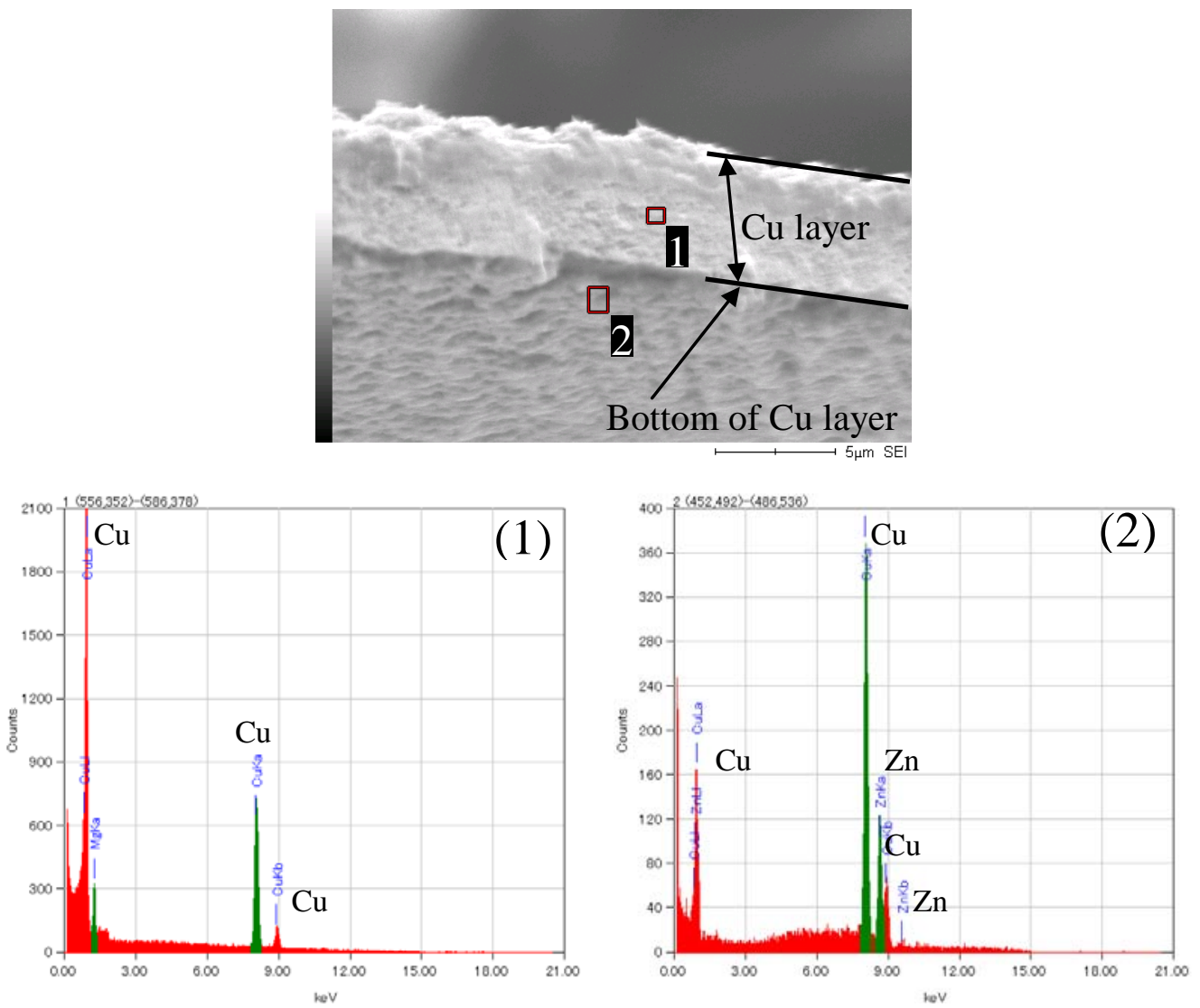

Fig. 9. Upper: Cross-sectional SEM images of the Cu layer peeled off from the AZ91 D Mg alloy specimen after the pull-off test. Lower: EDS analysis of the Cu layer at different positions (1) and (2). 

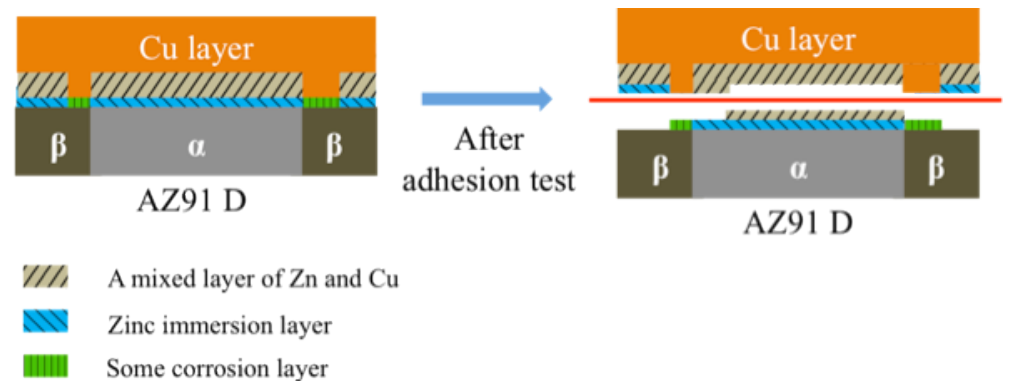

Fig. 10 (Color online) Schematic representation of peeling-off of the Cu electroplating layer from the AZ91 D Mg alloy surface zincate-pretreated with ultrasonic agitation. 